IGUSABDER, 13 (2021): 30-41

\title{
Adneksiyal Kitlelerde Preoperatif Tanı ile Postoperatif Histopatolojik Tanıların Retrospektif Karşılaştırılması
}

\author{
Ayşe KONAÇ*, Abdullah Yüksel BARUT**
}

\section{$\ddot{\mathbf{O z}}$}

Amaç: Adneksiyal kitlesi olan vakalarda kitlenin benign-malign açısından ayrımı yapılmalıdır. Over kanseri vakalarında genellikle erken belirtilerinin olmaması nedeni ile geç tanı konulması bu hastalığın prognozunun kötü seyretmesine neden olduğu için önem taşımaktadır. Bu retrospektif çalışma, benign-malign adneksiyal kitleleri preoperatif dönemde daha iyi tanımlayabilmek, adneksiyal kitlenin malignite olasılı̆̆ını daha yüksek oranda öngörmek amaçlı yapılmıştır.

Yöntem: Çalışmaya retrospektif olarak 3 yll içinde İstanbul Eğitim ve Araştırma Hastanesi Kadın Hastalıkları ve Doğum Kliniğine başvuran 570 hasta dahil edilmiştir. Bu çalışmada ultrasonografik bulgular (bilateralite, solid komponent, asit varlığı, metastaz varlığı, multilokülarite), CA125 değerleri ve hastanın yaş durumu incelenerek Malignite Risk İndeksi (RMI) değeri hesaplanmış, bu değerler postoperatif histopatolojik tanılarla karşılaştırılmıştır.

Bulgular: Ultrasonografik bulgular değerlendirildiğinde bilateral ve solid alan varlığının malignite açısından anlamlı olduğu görülmüştür. Malign ve benign kitlelerde RMI değerleri arasında anlamlı fark olduğu görülmüştür ( $p<0,001)$. Malignite açısından; CA-125, yaş ve ultrason skoruna oranla daha anlamlı olduğu ve elde edilen eşik değerlerin, baz alınan değerlere göre daha yüksek duyarlılıkta olduğu saptandı. Epitelyal kökenli malign over tümörleri ile epitelyal kökenli olmayan malign over tümörleri arasında RMI değerleri arasında anlamlı fark olduğu saptanmıştır ( $\mathrm{p}<0,001)$.

\footnotetext{
Özgün Araştırma Makalesi (Original Research Article)

Geliş / Received: 19.09.2020 \& Kabul / Accepted: 14.01.2021

DOI: https://doi.org/10.38079/igusabder.797365

${ }^{*}$ Dr. Öğr. Üyesi, İstanbul Gelişim Üniversitesi, Sağllk Bilimleri Fakültesi, İstanbul, Türkiye, E-posta: akonac@gelisim.edu.tr ORCID https://orcid.org/o0oo-0002-9119-3332

** Dr. Öğr. Üyesi, İstanbul Gelişim Üniversitesi, Sağllk Bilimleri Fakültesi, İstanbul, Türkiye, E-posta: aybarut@gelisim.edu.tr ORCID https://orcid.org/0000-0002-7861-0736
} 
Sonuç: Preoperatif dönemde yüksek speksifite ve sensiviteye sahip olan, kolay, ek masraf gerektirmeyen ve herhangi bir invaziv işleme gerek duymadan hesaplanan RMI ile malign adneksiyal kitlelerin daha yüksek bir oranda doğru öngörü oluşturarak, adneksiyal kitlelerin daha iyi yönetilmesini sağlayacaktır.

Anahtar Kelimeler: Over kanseri, adneksiyal kitle, ultrasonografi.

\title{
Retrospective Comparison of Preoperative Diagnosis and Postoperative Histopathological Diagnoses in Adnexal Masses
}

\begin{abstract}
Aim: In cases with adnexal mass, it should be differentiated from the benign-malignant mass. Due to the absence of early symptoms in ovarian cancer cases, late diagnosis is important because the prognosis of this disease is poor. This retrospective study was conducted to better define benign-malignant adnexal masses in the preoperative period and to predict the malignancy probability of adnexal mass at a higher rate.

Methods: 570 patients who applied to the Istanbul Training and Research Hospital Gynecology and Obstetrics Clinic in three years as retrospective were included in this study. In this study, the risk of malignancy index (RMI) value was calculated by examining the ultrasonographic findings (bilaterality, solid component, presence of acid, presence of metastasis, multilocularity), CA125 values and the age of the patient, and these values were compared with postoperative histopathological diagnoses.

Results: When the ultrasonographic findings were evaluated, it was seen that the presence of bilateral and solid areas was significant in terms of malignancy. It was observed that there was a significant difference between RMI values in malignant and benign masses ( $p<0,001)$. In terms of malignancy; CA-125 was found to be more significant compared to age and ultrasound score, and the threshold values obtained were found to be more sensitive than the baseline values. It was found that there was a significant difference in RMI values between epithelial origin malignant ovarian tumors and non-epithelial malignant ovarian tumors ( $\mathrm{p}<\mathrm{0}, \mathrm{OO1})$.
\end{abstract}

Conclusion: RMI, which has high specificity and sensitivity in the preoperative period, is easy, does not require additional costs and is calculated without the need for any invasive procedure, and will allow a better management of adnexal masses by creating a higher rate of correct prediction of malignant adnexal masses.

Keywords: Ovarian cancer, adnexal mass, ultrasonography. 


\section{Giriş}

Adneksiyal kitle jinekolojide sıkça rastlanan bir problemdir. Adneksler, broad ligament, overler ve fallop tüplerinden oluşur. Bu bölgeden köken alan kitlelerde genel olarak malignite potansiyeli olduğu için kanserle ilişkili mortaliteyi azaltmak ve erken tanıyı öncelikli olmalıdır. Adneksiyal kitleler genellikle over dokusundan kaynaklanır. Fallop tüplerinden malignensi nadiren gelişir ${ }^{1}$.

Over kanserinde genellikle hastalara geç tanı konulduğu için prognoz kötü seyreder². Beş yıllık yaşam oranı over kanserli hastalarda \%93, uzak metastazlarda ise \%28 oranında görülmektedir. Over kanserleri, diğer jinekolojik kanserlerden farklı olarak, erken belirti vermez bu nedenle hastaların büyük bir kısmı genellikle Evre III-IV’de yakalanır ${ }^{\text {. Eğer }}$ erken dönemde tanınabilirse, hastanın yaşam süresi uzatılabilir. Bu hastaların daha erken dönemde yakalanabilmeleri için yeni tanısal yöntemlerinin geliştirilmesi gereklidir.

Jinekoloji polikliniklerinde adneksiyal kitle tanısı sık konulmaktadır. Bu kitlelerin genellikle \%90’ benign karakterlidir ${ }^{4}$. Ancak yaşla birlikte, adneksiyal kitlenin malign olma oranı da artar. Ultrasonografinin yaygın olarak kullanılmaya başlanılması ile birlikte dünyada teknolojinin de ilerlemesi, adneksiyal kitlelerin erken yakalanma oranında artmaya yol açmış ve opere edilmeden yalnızca ayaktan takip edilen adneksiyal kitleli hastaların sayısında artış gözlenmiştir.

Tümörlerin benign ya da malign olup olmadıklarının ayırımı için bu tetkikler önemlidir. Pelvik kitlelerde bu ayrımın yapılması önemlidir özellikle malign kitlelerde preoperatif olarak yapılacak operasyon şeklinin belirlenmesine yardımcı olur.

Değerlendirme için kullanılan testlerin en önemlileri ultrasonografi ve kanda tespit edilen bir tümör markeri olan CA-125'dir.

CA-125 ilk kez 1981 yılında Bast ve arkadaşları tarafından bulunmuş ve over kanseri tanısı alan hastalarda teşhiste ve prognoz takibinde kullanılmaya başlanmıştır ${ }^{5}$. Genel olarak serum CA-125 düzeyi ileri evre over kanserlerinde \%8o oranında yükselir ve cutoff değer olarak 35 U/ml olarak kabul edilirse sensitivitesi ortalama \%81'dir. Eğer CA125 ve ultrasonografi birlikte kombine edilirse daha yüksek doğruluk payı elde edilebilir. USG nin sensitivitesi yaklaşık \%89 ve özgüllüğü \%73 olarak tanımlanmıştır. 
Transvaginal Ultrasonografi Adneksiyal kitlelerin değerlendirilmesinde daha yüksek sensitiviteye sahip olması nedeniyle Transabdominal Ultrasonografiye göre daha iyi sonuçlar verdiği kabul edilmektedir 6 .

Bu yöntemler birlikte yapılırsa adneksiyal kitlelere tanı koyabilme oranı yükselmektedir. Renkli Doppler Ultrasonografi nin adneksiyal kitlelerin değerlendirilmesinde normal Ultrasonografiye göre daha faydalı olabileceği bildirilmiştir6. 1991 yılında Sassone ve ark. ${ }^{7}$ transvajinal ultrasonografi ile over kaynaklı kitlelerin bening-malign ayrımında skorlama sistemi bildirmişlerdir. Bu sistem, adneksiyal kitlenin duvar kalınlı̆̆ı, kistik septanın ultrasonografik özellikleri ve ekojenitesi tespitine dayanıyor. Hesaplanan toplam puan tümörün niteliği ve davranışı hakkında bilgi vermekte ve malign tümörler benign tümörlerden bu sayede ayırd edilebilmektedir ${ }^{8}$.

\section{Gereç ve Yöntem}

Çalışmada adneksiyal kitle tanısı konulan ve bu nedenle opere edilen hastalarda preoperatif yöntemlerle malignite riskinin retrospektif olarak araştırılması ve postoperatif histopatolojik tanılarla karşılaştırılması amaçlanmıştır. İstanbul Eğitim ve Araştırma Hastanesi Kadın Hastalıkları ve Doğum Kliniğine 3 yıl içinde başvuran, adneksiyal kitle ön tanısı nedeniyle opere edilen 570 hasta çalışmaya dâhil edilmiştir. Bu çalışma için İstanbul Gelişim Üniversitesi Etik Kurulundan 11.09.2020 tarih ve 2020-24 sayılı Etik Kurul Onayı alınmıştır.

Metastatik Over CA nedeniyle takip edilen hastalar çalışmaya dâhil edilmedi. Ultrasonografi ve Doppler Ultrasonografi ile yapılan incelemede, Toshiba marka Ultrasonografi cihazı ile abdominal prob ve vajinal problar kullanıldı. Bütün vakalar Jinekoloji Kliniği tarafından değerlendirildi. Genel olarak tüm adneksiyal kitlelerde kitlenin boyutu, bilateral ya da solid komponent olup olmadığı, asit varlığı, duvar yapısı ve kalınlığı, septasyon varlığı ve varsa kalınlığı, papiler yapılar içerip içermediği, metastaz düşündürecek batında asit varlığı ve varsa ekojenitesi kaydedildi. Doppler ölçümlerinde RI (Rezistans indeksi) ve PI (Pulsatilite indeksi) hesaplaması kullanıldı. RI için <0,4 ve PI için eşik değer < 1 malignite kriteri kabul edildi. Buna göre Ultrasonografik olarak bilateralite, multiloküle, solid komponent varlığı, asit varlığı ve metastaz varlığı olup olmadığı tespit edildi. 
Adneksiyal kitlesi olan vakalarda serum CA-125 seviyeleri preoperatif olarak kaydedildi. Testler İstanbul Eğitim ve Araştırma Hastanesi Laboratuvarlarında yapıldı.

Dünya Sağlık Örgütü’nün (WHO) kriterlerine göre tümörler sınıflandırıldı. Alınan materyaller "frozen section" ve postoperatif histopatolojik olarak değerlendirildi. Histopatolojik tanı, tanı için altın standart olarak kabul edildi.

\section{Bulgular}

Histopatolojik sonuçlara göre 446 benign (\%78), 28 borderline (\%5) ve 96 malign (\%17) kitle incelendi. Borderline tümörü olan vakalar malign tümörler grubuna dâhil edildi. Çalışmada malignite oranı \%17 olarak bulundu. Malign kitlelerdeki erken evre olguların (evre 1-2 over tümörleri) oranı \%43 olarak tespit edilirken; ileri evre olguların (evre III, IV ve metastatik over tümörleri) oranı ise \%57 olduğu izlendi. 446 benign adneksiyal kitleli olguların yaşları 19-78 (ort 48) iken; 124 malign adneksiyal kitleli olguların yaşları 36-78 (ort 57) olduğu görülmüştür (Tablo 1).

Tablo 1. Benign ve malign grupta yaş ortalamalarının karşılaştırması

\begin{tabular}{|l|c|c|c|c|c|c|}
\hline Davranış & n & Ort. & SD & Min & Max & P değeri \\
\hline Benign & 446 & 48 & 16.2 & 19 & 78 & \\
Malign & 124 & 57 & 13.8 & 36 & 78 & $\mathrm{p}<0,05$ \\
Toplam & 570 & 53 & 15 & 27.5 & 90 & \\
\hline
\end{tabular}

Tüm adneksiyal kitlelerdeki yaş ortalaması p<0,001 olmasıyla iki grup arasında anlamlı fark görüldü. Toplam adneksiyal kitlelerin histopatolojik tanılarına göre dağılımı Tablo 2'de verilmiştir. Bu tabloya göre toplam adneksiyal kitlelerdeki histopatolojik dağılım yapılmıştır. Benign adneksiyal kitleler daha fazla tespit edilmiştir. Bunlar içerisinde seröz kistadenom 132 adet (\%43) ve dermoid kist 72 adet $(\% 7,9)$ olup aynı oranda olduğu izlenirken, ikinci sırayı ise 48 adet $(\% 11,8)$ izlenen seröz kist adenokarsinom almıştır. Bunu sırasıyla müsinöz kist adenom, hemorajik kist takip etmiştir. 
Tablo 2. Adneksiyal kitlelerin histopatolojik dağılımı

\begin{tabular}{|l|l|l|l|l|}
\hline Histolojik tip & Sayı (n) & Yüzde (\%) & Total \% & Kumulative \% \\
\hline Seröz kistadenom & 92 & 16 & 16 & 16 \\
\hline Müsinöz kistadenom & 44 & 8 & 8 & 24 \\
\hline Endometrioma & 58 & 10 & 10 & 34 \\
\hline Hemorajik kist & 26 & 4,5 & 4,5 & 38,5 \\
\hline Seröz kist & 53 & 9,5 & 9,5 & 48 \\
\hline Brenner tümörü & 2 &, 5 &, 5 & 48,5 \\
\hline Torsiyone over & 14 & 2,5 & 2,5 & 51 \\
\hline Seröz kistadeno ca & 59 & 10,1 & 10,1 & 61,1 \\
\hline Müsinöz kistadeno ca & 32 & 5,5 & 5,5 & 66,1 \\
\hline Borderline tümör & 48 & 8,1 & 8,1 & 74.2 \\
\hline Dermoid kist & 58 & 10,5 & 10,5 & 86,7 \\
\hline Fibrom & 31 & 5,5 & 5,5 & 90,2 \\
\hline Abse materyali & 4 &, 6 &, 6 & 90,8 \\
\hline Epitelyal adenoca & 15 & 2,7 & 2,7 & 93,5 \\
\hline Struma ovari & 3 &, 5 &, 5 & 94 \\
\hline Granüloza hücreli tm. & 12 & 2,2 & 2,2 & 96,3 \\
\hline Taşlı yüzük hcli karsinom & 1 &, 4 &, 4 & 96,7 \\
\hline Karsino sarkom & 14 & 2,4 & 2,4 & 99 \\
\hline Kist hidatik & 1 &, 4 &, 4 & 99,6 \\
\hline Epidermoid adenoca infiltrasyonu & 3 &, 5 &, 5 & 100,0 \\
\hline Total & 570 & 100,0 & 100,0 & 100,0 \\
\hline
\end{tabular}

Benign adneksiyal kitlelerin dokulara göre dağılımı Tablo 3’te gösterilmiştir. 
Tablo 3. Benign adneksiyal kitlelerin dokulara göre dağılımı

\begin{tabular}{|l|c|c|}
\hline \multicolumn{1}{|c|}{ Histolojik tip } & Vaka sayısı & \% \\
\hline Borderline tümörler & 48 & 100 \\
Seröz borderline tümör & 39 & 82,2 \\
Müsinöz borderline tümör & 9 & 18,8 \\
\hline Total & 48 & 100 \\
\hline Malign tümörler & 136 & 100 \\
\hline Epitelyal tümör & 106 & 78 \\
Epitelyal adenokarsinom & 15 & 11 \\
Seröz kistadenokarsinom & 59 & 43,1 \\
Müsinöz kistadenokarsinom & 32 & 23,9 \\
Sex-kord stromal tümör & 12 & 9 \\
Granüloza hücreli tümör & 12 & 9 \\
Metastatik over tümörleri (kolon, mide, & 4 & 3 \\
serviks) & 3 & 2,3 \\
Epidermoid karsinom & 1 & 0,7 \\
Taşlı yüzük hücreli karsinom & 14 & 10 \\
\hline Diger & 14 & 10 \\
Karsinosarkom & & \\
\hline
\end{tabular}

Malign-Borderline tümörlerin dokulara göre dağılımı Tablo 4’te gösterilmiştir.

Tablo 4. Malign- Borderline tümörlerin dokulara göre dağılımı

\begin{tabular}{|l|c|c|}
\hline \multicolumn{1}{|c|}{ Histolojik tip } & Sayı (n) & Yüzde(\%) \\
\hline Nonneoplastik & 102 & 26,1 \\
\hline Hemorajik over kisti & 26 & 6,9 \\
Endometrioma & 58 & 15 \\
Tubaoveryan & 4 & 1,9 \\
Abse/hidrosalpix & & \\
Torsiyone over dokusu & 14 & 2,3 \\
\hline Neoplastik & 283 & 73,6 \\
\hline Germ hücreli tümörler & 61 & 16 \\
Matür kistik teratom & 58 & 15,2 \\
Struma ovarii & 3 & 0,8 \\
Epitelyal tümörler & 191 & 49,4 \\
\hline
\end{tabular}




\begin{tabular}{|l|c|c|}
\hline Seröz kist & 53 & 13,5 \\
Seröz Kistadenom/adenofibrom & 92 & 23,9 \\
Müsinöz kistadenom & 44 & 11,5 \\
Brenner tümörü & 2 & 0,5 \\
Sex-kord stromal tümör & 31 & 8,1 \\
Fibrom & 31 & 8,1 \\
\hline Diğer & 1 & 0,3 \\
Kisthidatik & 1 & 0,3 \\
\hline Total & 386 & 100 \\
\hline
\end{tabular}

Menopoz durumuna göre incelendiğinde (Tablo 5), olguların 342’i $(\% 66,5)$ premenopozal, 228’i ise $(\% 33,5)$ postmenopozal olduğu görülmüştür. Premenopozal olgularda 230 adet $(\% 67,6)$ benign adneksiyal kitleli olgular izlenirken, 112 adet $(\% 32,4)$ malign adneksiyal kitleli olgular izlenmiştir. Postmenopozal olgularda ise, 156 adet $(\% 68,4)$ benign adneksiyal kitleli vakalar izlenirken, 72 adet $(\% 31,6)$ malign adneksiyal kitleli olan olgu izlendi. İki grup arasında anlamlı fark vardı ( $\mathrm{p}<0,001)$. Adneksiyal Kitleli hastalara yapılan Ultrasonografilerde solid komponent benign adneksiyal kitlesi olan 131 hastada (\%38) izlenirken, malign adneksiyal kitlesi olan 148 hastada $(\% 78,4)$ solid komponent varlığı olduğu görülmüştür. Bilateralite incelendiğinde ise benign adneksiyal kitlesi olan 15 vakada $(\% 11,2)$ olduğu görülürken, malign adneksiyal kitlesi olan 78 vakada $(\% 42,4)$ izlenmiştir.

Tablo 5. Menopoz durumuna göre dağılım

\begin{tabular}{|c|c|c|c|c|}
\hline Tip & \multicolumn{2}{|c|}{ Premenopoz } & \multicolumn{2}{c|}{ Postmenopoz } \\
\hline & n & \% & n & \% \\
\hline Benign & 230 & 67,6 & 156 & 68,4 \\
\hline Malign & 112 & 32,4 & 72 & 31,6 \\
\hline Total & 342 & 100 & 228 & 100 \\
\hline
\end{tabular}

İki grup arasında anlamlı fark olduğu saptanmıştır ( $<<0,001)$. Ultrasonografi de asit varlığı incelendiğinde; benign adneksiyal kitlesi olan 28 vakada $(\% 8,2)$ görülürken, malign adneksiyal kitlesi olan 96 vakada $(\% 52,4)$ olduğu anlaşılmıştır. İki grup arasında anlamlı fark olduğu saptanmıştır ( $\mathrm{p}<0,001)$. 
Metastaz ile uyumlu görünüm ise benign adneksiyal vakalarda hiç izlenmezken, malign adneksiyal kitlesi olan $18(\% 9,9)$ vakada olduğu görülmüştür. İki grup arasında anlamlı fark olduğu saptanmıştır ( $\mathrm{p}<0,001)$ (Tablo 6).

Tablo 6. Ultrasonografik morfolojik bulguların dağılımı

\begin{tabular}{|l|c|c|c|}
\hline Ultrasonografik Morfoloji & Benign & Malign & p \\
\hline Bilateralite & $15(\% 11,2)$ & $78(\% 42,4)$ & 0,001 \\
\hline Solid komponent & $131(\% 38)$ & $148(\% 78,4)$ & 0,001 \\
\hline Asit varlığı & $28(\% 8,2)$ & $96(\% 52,4)$ & 0,001 \\
\hline Metastaz varlığı & $0(\% 0)$ & $18(\% 9,9)$ & 0,001 \\
\hline
\end{tabular}

Ultrasonografik kriterler değerlendirildiğinde (Tablo 6) en az olan multilokülarite olduğu ve buna göre multilokülarite varlığında maligniteyi öngörme olasılığının olmadığı görüldü. Solid alan varlığı ise maligniteyi düşündürme açısından önemli bir ultrasonografik kriter olduğu görüldü. Bunu asit varlığı takip ederken, sonraki sırada bilateralite olduğu gözlendi.

Preoperatif dönemde ölçülen serum CA-125 değerleri benign adneksiyal kitlesi olan 131 hastada (\%38) 35 ve üstü iken; malign adneksiyal kitlesi olan 141 olguda $(\% 76,8)$ bu değerin üzerinde olduğu görülmüştür. Böylelikle iki grup arasında anlamlı düzeyde fark olduğu görülmüştür. ( $\mathrm{p}<0,001$ ) Borderline tümörlerde ise 23 vakada (\% 48) CA-125 değerinin 35 ve üstünde olduğu izlenmiş olup; anlamlı bir fark olduğu görülmemiştir (Tablo 7).

Tablo 7. CA 125 değerine göre tiplendirme

\begin{tabular}{|c|c|c|c|c|c|c|}
\hline \multirow[t]{3}{*}{ Tip } & \multicolumn{4}{|c|}{ CA 125} & \multicolumn{2}{|c|}{ Total } \\
\hline & & & & & & \\
\hline & $\mathbf{n}$ & $\%$ & $\mathbf{n}$ & $\%$ & $\mathbf{n}$ & $\%$ \\
\hline Benign & 215 & 78 & 131 & 44 & 346 & 100 \\
\hline Malign & 43 & 16 & 141 & 48 & 184 & 100 \\
\hline Borderline & 17 & 6 & 23 & 8 & 40 & 100 \\
\hline Total & 275 & 100 & 295 & 100 & 570 & 100 \\
\hline
\end{tabular}




\section{Tartışma}

Genel olarak 4’üncü en sık görülen jinekolojik tanının adneksiyal kitle olduğu görülmüşsür. Bu kitlelerin yaklaşık \%9o’ı benigndir. Over kanseri tüm jinekolojik malign kanserler arasında en yüksek mortaliteye sahiptir ${ }^{8}$. Yaşamı boyunca bir kadının over kanserine yakalanma riski 1/72'dir9 .

Erken evrede semptomların nadir olması nedeniyle tanı için birçok biyokimyasal tetkik ve görüntüleme yöntemi araştırılmaktadır. Ultrasonografinin yaygın olarak kullanılması ile preoperatif dönemde hastalarda adneksiyal kitle daha çok tespit edilmiş ve malignite riski az olan hastaların ameliyat edilmeden USG takipleri ile izlenebileceği anlaşılmıştır. Malign over tümörleri genel olarak daha yaşlı hastalarda, benign over tümörleri ise daha genç hastalarda görülmektedir. Malign epitelyal over tümörleri genellikle 60-70 yaş arasında pik yapar ve genellikle 40 yaşının altında daha az görülürler ${ }^{10}$. Çalışmada 446 benign adneksiyal kitleli olguların yaşları 19-78 (ort 48) iken; 124 malign adneksiyal kitleli olguların yaşları 36-78 (ort 57) olduğu görülmüş ve menopoz skoru için sensitivite \%78 iken, spesivite ise \%75 olarak hesaplanmıştır. Çalışmadaki verileri, literatürdeki diğer verilerle benzer bulunmuştur. Çalışmada menopoz skoru malignite ile yakından ilişkili bulunmuştur. Ultrasonografi adneksiyal kitlelerin ayırıcı tanısında en sık kullanılan görüntüleme yöntemidir.

Sassone ve arkadaşları7, over kistlerini ultrasonografi kullanarak benign ve malign olmak üzere iki grupta değerlendirmiştir. 143 hastada transvaginal sonografi yapmışlardır. Kist iç duvarı, duvar kalınlığı, multilokülariteyi ve ekojeniteyi kriter olarak alınmamıştır. Duyarlılık \%100, özgüllük \%83 olarak rapor edilmiştir. Timmermen ve arkadaşları ${ }^{11}$, yaptıkları bir çalışmada \%95,9 duyarlılık, \%87,1 özgüllük bulmuşlardır. Bu kriterlere Sassone kriterlerine ek olarak boyut, volüm, hemorajik kist, akustik gölgelenme gibi kriterler kullanılmış ve kitleleri multikistik, unilokuler kistik, multiloküler, multilokuler solid olarak ayırmışlardır.

Çalışmada, Jacobs ve ark. tarafından kullanılan kriterleri (bilateralite, solid alan varlığı, asit varlığı, metastaz, multilokülarite) kullanılmıştır. Malignite için anlamlı bulunan $\mathrm{U}=3$ (2-5) için çalışmada sensitivite \%80, spesivitenin ise \%82 civarı olduğu görülmüştür. Bu değerlerin literatürdeki diğer değerlerle uyumlu olduğu söylenebilir. Ultrason skoru 
verileri ayrı ayrı kıyaslandığında bilateralite ve solid alan varlığı maligniteyi öngörme açısından anlamlılığının yüksek olduğu görüldü.

Çalışmada, malignite için prediktivitesi yüksek olan kriterlerden serum CA-125 düzeyi $35 \mathrm{u} / \mathrm{ml}$ kabul edildiğinde ise sensitivitenin \%81, spesivitenin ise \%68 olduğu görülmüştür. Bu çalışmada, CA-125’inin spesivitesinin daha düşük olmasının sebebi overin malign tümörleri dışında birçok faktörün bu markırın artışına neden olmasındandır. Diğer çalışmalarda CA-125 düzeyi $35 \mathrm{u} / \mathrm{ml}$ kabul edildiğinden bu çalışmada bu eşik değerini kullanılmıştır.

\section{Sonuç}

Over kanseri jinekolojik kanserler sıralamasında en sık gözlenen ikinci jinekolojik kanserdir. Kadınlardaki kanser ölümlerine bağlı beşinci sırada ve jinekolojik malignitelerin içerisinde ise en yüksek mortaliteye sahiptir. Diğer tüm vakalarda olduğu gibi kesin tanı yalnızca histopatoloji ile konulabilir.

Çalışmada, yaş ile birlikte ve postmenopozal dönemdeki adneksiyal kitlelerde malignite olasılığının da arttığını saptanmıştır. Postmenopozal hastalarda malign kitlelerin daha sık saptandığını görülmüştür. Yaş için 53'ün eşik değer olabileceğini, ancak iki grup arasında anlamlı fark olmadığı tespit edildi. Serum CA 125 düzeyinin malign kitlelerin histopatolojik tanılarıyla karşılaştırmada etkili olduğu saptanmıştır. CA-125 düzeyinin $35 \mathrm{U} / \mathrm{ml}$ olduğunda sensitivitesi ortalama \%81, spesivitesi \%68 teşhiste anlamlı olacağı görülmüştür.

Menopoz skoru, ultrason skoru ve CA-125 düzeyi ile hesaplanan RMI'nın maligniteyi öngörme açısından diğerlerine kıyasla daha anlamlı olduğu saptanmıştır. RMI 200 eşik değer kullanıldığında sensitivitesi \%87, spesivitesi \%80 olarak saptanmıştır.

Önceki çalışmalarda benign-malign epitelyal tümörlerle, epitelyal kökenli olmayan tümörler arasında RMI değerleri arasında anlamlı bir fark olmadığı tespit edilmişti. Bu çalışmada ise, benign epitelyal kökenli tümörlerle epitelyal kökenli olmayan tümörler arasında RMI değerleri arasında fark görülmemesine rağmen; malign epitelyal tümörlerle epitelyal kökenli olmayan tümörler arasında anlamlı fark olduğu saptandı. Dolayısıyla RMI özellikle malign epitelyal kökenli tümörleri öngörme açısından anlamlı olduğu tespit edildi. 


\section{KAYNAKLAR}

1. Grab D, Flock F, Stohr I, et al. Classification of asymptomatic adnexal masses by ultrasound, magnetic resonance imaging, and positron emission tomography. Gynecol Oncol. 2000;77:454-9.

2. Koonings PP, Campbell K, Mishell DR Jr, Grimes DA. Relative frequency of primary ovarian neoplasms: a 10 year review. Obstet Gynecol. 1989;74:921-6.

3. Kisnisçi A, Göksin E. Malign over tümörleri. Temel Kadın Hastalıkları ve Doğum. 2008;12:58-62.

4. Abu-rustum NR, Aghajanian C. Menagement of malignant germ cell tumors of the ovary. Semin Oncol. 1998;25(2):235-42.

5. Miller BA, Ries LAG, Hankey BF, et al. SEER cancer statistics review 1973-1995. Bedhesta (MD): National Cancer. 1998;31:42-53.

6. Holschneider $\mathrm{CH}$, Berek JS. Ovarian cancer: epidemiology, biology and prognostic factors. Semin Surg Oncol. 2000;19:3-10.

7. Sassone AM, Timor-Tritsch IE, Artner A, Westoff C, Warren WB. Transvaginal sonographic characterization of ovarian disease: evaluation of a new scoring system to predict ovarian malignancy. Obstet Gynecol. 1991;78(1):70-6.

8. Grab RT, Hill-Harmon MB, Murray T, Thun M. Cancer statistics, ultrasound 2001. CA Cancer J Clin. 2001;51:15-36.

9. Turgut A, Özler A, Sak ME, et al. Jinekolojik kanserli olguların retrospektif analizi:11 ylllk deneyim. J. Clin Exp Invest. 2012;3:209-213.

10. Kurjak A, Shalon H, Kupesic S, et al. Tranvaginal color doppler sonography in the assesment of pelvic tumor vascularity. Ultrasound Obstet Gynecol. 2003;3:13754 .

11. Timmerman D, Bourne TH, Tailor A, Collins WP, Verrelst H, Vandenberhe K. A comparison of methods for preoperative discrimination between malignant and benignadnexal mases: the development of a new logistic regression model. Am J Obstet Gynecol. 2007;181(1):57-65. 